\title{
Significant prognostic value of circulating tumor cells in esophageal cancer patients: A meta-analysis
}

\author{
Shuyu Wang ${ }^{1}$, Hongyang $\mathrm{Du}^{2}$, Guixia $\mathbf{L i}^{1}$ \\ ${ }^{1}$ Medical Laboratory Department, Heze Municipal Hospital, Heze, Shandong, 274031 China \\ ${ }^{2}$ Heze Centre for Adverse Drug Reactions Monitoring, Heze, Shangdong, 274000, China \\ Correspondence to: Shuyu Wang, email: shuyu312@163.com \\ Keywords: esophageal cancer, circulating tumor cells, meta-analysis
}

Received: July 10, 2016

Accepted: January 03, 2017

Published: February 02, 2017

\section{ABSTRACT}

\begin{abstract}
Esophageal cancer is the sixth leading cause of cancer death worldwide. Detection of circulating tumor cells (CTCs) is emerging as a novel strategy for predicting cancer patient prognosis. Here we performed a comprehensive literature search to identify relevant articles in EMbase, PubMed, EBSCO, OVID, Cochrane Database, CNKI, WanFangdata and VIPdata. Meta-analysis was conducted using Stata12.0 software, according to the inclusion and exclusion criteria, extracted data and assessment methodology. Thirteen eligible literature studies were included with a total of $\mathbf{9 7 9}$ esophageal squamous cell carcinoma patients, including 424 CTC-positive and 684 CTC-negative cases. Meta-analysis showed that the presence of CTCs was associated with both worse progression-free/disease-free survival [hazard ration $(H R)=2.32$, $95 \%$ confidence interval $(\mathrm{CI})=1.57-3.43, \mathrm{p}<0.001$ ] and poorer overall survival $[\mathrm{HR}$ $=2.64,95 \% \mathrm{CI}=1.69-4.14, \mathrm{p}<0.001]$. Further subgroup analyses demonstrated that CTC-positive patients also showed worse progression-free/disease-free survival and poorer overall survival in different subsets. In summary, our metaanalysis provides strong evidence that detection of CTCs in the peripheral blood is an independent prognostic indicator of poor outcome for esophageal squamous cell carcinoma patients.
\end{abstract}

\section{INTRODUCTION}

Esophageal cancer is the eighth most frequently diagnosed cancer and the sixth leading cause of cancer death worldwide [1]. Patients with esophageal cancer, compared with those with other cancers, have poorer prognosis because of earlier recurrence and metastasis $[2$, 3]. Even esophageal cancer patients with no metastasis detectable in the clinic at the time of diagnosis may still die of cancer recurrence after surgery $[4,5]$. This suggests that esophageal cancer spreading or metastasis cannot be detected by conventional biochemistry testing, imaging or histopathological methods.

Metastasis involves cancer cell separation from the primary tumor, invasion through the basal membrane into a blood or lymphatic vessel, survival in circulation, extravasation, and colonization of distant metastatic sites. Peripheral blood circulating tumor cells (CTCs) are shed by a primary tumor into vasculature, keep circulating in the blood stream of cancer patients, and are likely to play a critical role in hematogenous metastasis [6]. Clinical implications of CTCs are dependent on the techniques used to isolate them. Each isolation technology has strengths and limitations regarding sensitivity and purity, and may yield different subpopulations of cells [7]. Although detection of CTCs is currently used in many clinical trials, their clinical utility is still under investigation, and a number of issues with regard to CTC detection and characterization remain unclear [8].

In recent years, studies of peripheral blood CTCs suggest that CTCs can be used to predict the progress and prognosis of esophageal cancer $[9,10]$. However, current research findings on esophageal CTCs are based on small cohorts of tumor specimen and results are inconsistent. Therefore, in this study, we have performed meta-analysis of worldwide published data to evaluate correlation between esophageal CTCs and patient prognosis. 


\section{RESULTS}

\section{Characteristics of 13 papers on esophageal squamous cell carcinoma CTCs}

Literature search was performed to identify articles on esophageal CTCs (Figure 1). A total of 1019 records were initially identified by the comprehensive literature search. After screening the titles and abstracts, 899 irrelevant records were filtered out, and 88 records were subsequently excluded because they were reviews, conference papers, or irrelevant research. There left 32 full-text articles for detailed evaluation, of which 19 studies were further excluded for being incompatible with inclusion criteria [11-15], without survival data to estimate HRs and 95\% CIs [1, 16-24,32] or with less than 20 samples [25-27] (Supplementary Table 1). Finally, 13 eligible studies were included for meta-analysis $[9,10$, 28-31, 33-39].

The 13 papers were published between 2006 and 2015 , with esophageal squamous cell carcinoma patient sample sizes ranging from 30 to 244 and a total of 979 patients, 424 CTC positive and 684 CTC-negative cases. Method used for CTC detection included RTPCR (reverse transcription-polymerase chain reaction), CellSearch CTC assay and IE/IF (immunomagnetic enrichment/immunofluorescence staining) approaches. RT-PCR markers for CTCs included carcinoembryonic antigen (CEA) mRNA, Survivin mRNA, squamous cell carcinoma antigen (SCCA) mRNA and cytokeratin (CK19) mRNA. Characteristics of the eligible studies were summarized in Table 1.

\section{CTC-positive patients show a higher risk of disease progression and worse overall survival than CTC-negative patients}

Before performing meta-analysis, heterogeneity tests (or homogeneity tests) were performed using the Cochran Q test and quantitative $I^{2}$ test among studies. It was found that both progression-free survival (PFS)/ disease-free survival (DFS) $\left(I^{2}=75.2 \%, \mathrm{p}=0.000\right)$ and

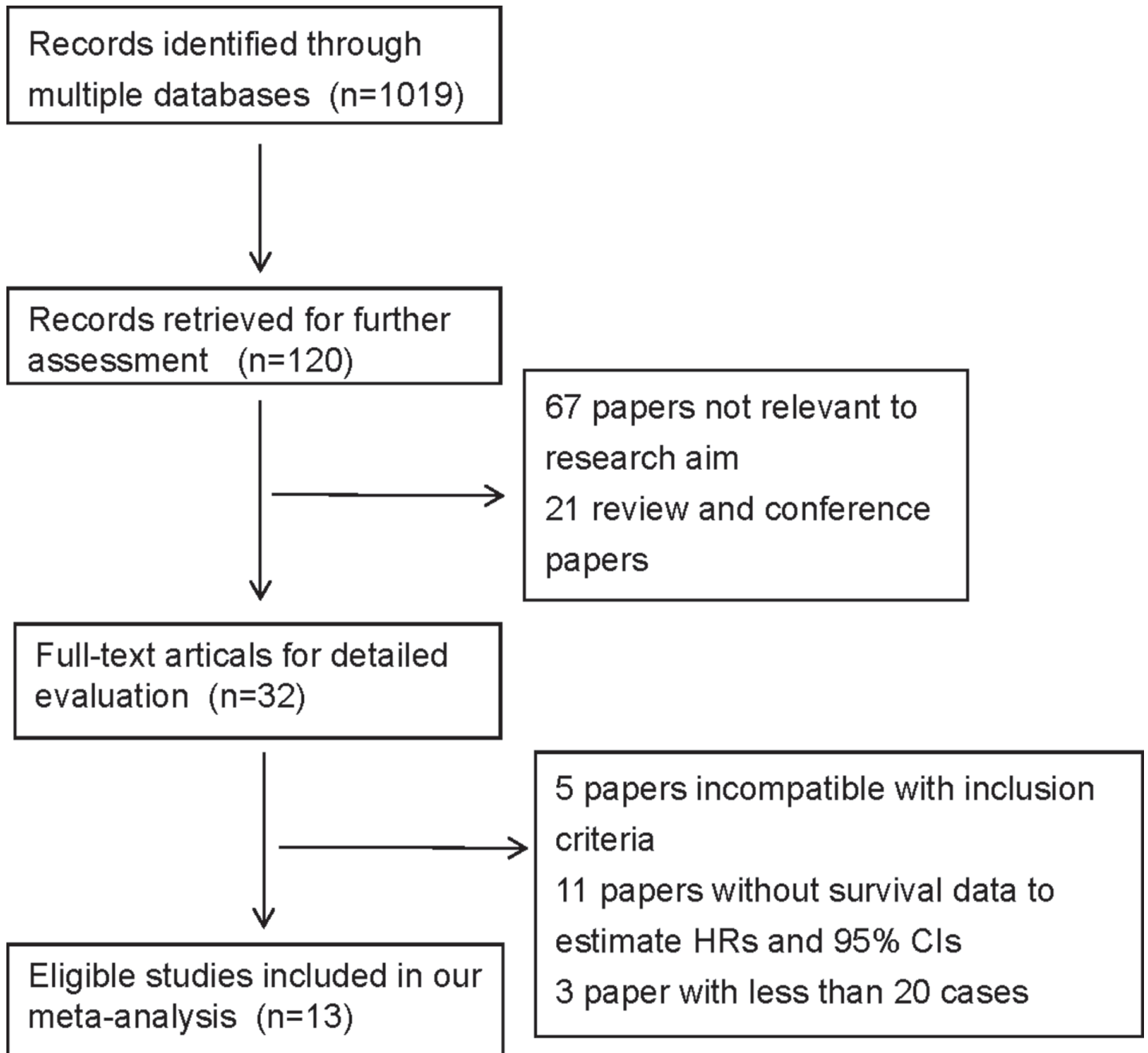

Figure 1: The flow chart of literature search. 
Table 1: Characteristics of the included studies

\begin{tabular}{|c|c|c|c|c|c|c|c|c|c|c|}
\hline Study & Country & $\begin{array}{l}\text { Sample } \\
\text { size }\end{array}$ & $\begin{array}{c}\text { Sampling } \\
\text { time }\end{array}$ & $\begin{array}{l}\text { Median } \\
\text { fellow-up } \\
\text { (month) }\end{array}$ & pTNM & $\begin{array}{l}\text { Detection } \\
\text { method }\end{array}$ & $\begin{array}{l}\text { Detection } \\
\text { rate, } \\
\%(\mathbf{n} / \mathbf{N})\end{array}$ & Outcomes & $\begin{array}{c}\text { HR \& } \\
95 \% \mathrm{CI} \\
\text { extraction }\end{array}$ & HR(95\%CI) \\
\hline \multirow[t]{2}{*}{$\begin{array}{l}\text { Setoyama T } \\
(2007)\end{array}$} & Japan & 125 & NR & 11.5 & I-IV & RT-PCR & $\begin{array}{c}61.6 \\
(77 / 125)\end{array}$ & DFS & $\begin{array}{c}\text { Data } \\
\text { extrapolated }\end{array}$ & $0.76(0.55,1.01)$ \\
\hline & & & & & & & & OS & $\begin{array}{c}\text { Data } \\
\text { extrapolated }\end{array}$ & $1.03(0.47,2.23)$ \\
\hline \multirow[t]{2}{*}{$\begin{array}{l}\text { Cao M } \\
(2009)\end{array}$} & China & 108 & Baseline & 19.5 & I-IV & RT-PCR & $\begin{array}{c}47.2 \\
(51 / 108)\end{array}$ & PFS & $\begin{array}{l}\text { Reported in } \\
\text { text }\end{array}$ & $5.18(2.42,8.93)$ \\
\hline & & & & & & & & OS & $\begin{array}{l}\text { Reported in } \\
\text { text }\end{array}$ & $5.17(2.30,11.65)$ \\
\hline \multirow[t]{4}{*}{$\begin{array}{l}\text { Tanaka K } \\
(2010)\end{array}$} & Japan & 244 & Baseline & 24.3 & I-IV & RT-PCR & $8.2(20 / 244)$ & DFS & $\begin{array}{c}\text { Data } \\
\text { extrapolated }\end{array}$ & $1.96(1.20,3.21)$ \\
\hline & & & & & & & & OS & $\begin{array}{c}\text { Data } \\
\text { extrapolated }\end{array}$ & $2.45(1.27,4.72)$ \\
\hline & & 244 & Post-therapy & 24.3 & I-IV & RT-PCR & $\begin{array}{c}13.5 \\
(33 / 244)\end{array}$ & DFS & $\begin{array}{c}\text { Data } \\
\text { extrapolated }\end{array}$ & $1.65(1.03,2.63)$ \\
\hline & & & & & & & & OS & $\begin{array}{c}\text { Data } \\
\text { extrapolated }\end{array}$ & $1.64(0.91,2.97)$ \\
\hline \multirow[t]{2}{*}{ Li J (2012) } & China & 48 & Baseline & 34 & I-IV & $\mathrm{IE} / \mathrm{IF}$ & $64.6(31 / 48)$ & PFS & $\begin{array}{c}\text { Data } \\
\text { extrapolated }\end{array}$ & $2.44(1.01,5.89)$ \\
\hline & & 48 & Post--therapy & 34 & I-IV & $\mathrm{IE} / \mathrm{IF}$ & $64.6(31 / 48)$ & PFS & $\begin{array}{c}\text { Data } \\
\text { extrapolated }\end{array}$ & $3.89(0.86,17.52)$ \\
\hline \multirow[t]{2}{*}{$\begin{array}{l}\text { Yin XD } \\
(2012)\end{array}$} & China & 72 & Baseline & 24 & I-III & RT-PCR & $52.7(34 / 72)$ & PFS & $\begin{array}{l}\text { Reported in } \\
\text { text }\end{array}$ & $3.68(1.37,9.84)$ \\
\hline & & 72 & Post--therapy & 24 & I-III & RT-PCR & $30.6(22 / 72)$ & PFS & $\begin{array}{l}\text { Reported in } \\
\text { text }\end{array}$ & $2.52(0.87,7.23)$ \\
\hline $\begin{array}{l}\text { Liao HL } \\
(2010)\end{array}$ & China & 62 & Baseline & 26.4 & I-III & RT-PCR & $16.1(10 / 62)$ & OS & $\begin{array}{l}\text { Reported in } \\
\text { text }\end{array}$ & $6.53(1.28,6.78)$ \\
\hline $\begin{array}{l}\text { Matsushita D } \\
\text { (2015) }\end{array}$ & Japan & 90 & Baseline & 10.3 & II-IV & CellSearch & $27.8(25 / 90)$ & OS & $\begin{array}{l}\text { Reported in } \\
\text { text }\end{array}$ & $2.91(1.44,5.80)$ \\
\hline $\begin{array}{l}\text { Hoffmann } \\
\text { AC (2010) }\end{array}$ & Germany & 25 & NR & 36 & I-IV & RT-PCR & 25 & OS & $\begin{array}{l}\text { Reported in } \\
\text { text }\end{array}$ & $10.9(1.53-77.50)$ \\
\hline $\begin{array}{l}\text { Honma H } \\
\text { (2006) }\end{array}$ & Japan & 46 & Baseline & 34 & I-IV & RT-PCR & $\begin{array}{c}30.43 \\
(14 / 46)\end{array}$ & PFS & $\begin{array}{l}\text { Reported in } \\
\text { text }\end{array}$ & $3.00(1.05,8.54)$ \\
\hline \multirow[t]{2}{*}{$\begin{array}{l}\text { Yuan X } \\
(2012)\end{array}$} & China & 72 & Baseline & 24 & I-III & RT-PCR & $54.2(39 / 72)$ & PFS & $\begin{array}{l}\text { Reported in } \\
\text { text }\end{array}$ & $2.26(0.86,5.86)$ \\
\hline & & 72 & Post--therapy & 24 & I-III & RT-PCR & $38.9(28 / 72)$ & PFS & $\begin{array}{l}\text { Reported in } \\
\text { text }\end{array}$ & $4.08(1.49,11.19)$ \\
\hline \multirow[t]{2}{*}{$\begin{array}{l}\text { Wang R } \\
(2012)\end{array}$} & China & 72 & Baseline & 24 & I-III & RT-PCR & $44.4(32 / 72)$ & PFS & $\begin{array}{l}\text { Reported in } \\
\text { text }\end{array}$ & $1.94(0.96,3.93)$ \\
\hline & & 72 & Post--therapy & 24 & I-III & RT-PCR & $30.6(22 / 72)$ & PFS & $\begin{array}{l}\text { Reported in } \\
\text { text }\end{array}$ & $2.35(1.16,4.75)$ \\
\hline \multirow[t]{2}{*}{ Xue R (2010) } & China & 57 & Baseline & 13 & I-III & RT-PCR & $29.8(17 / 57)$ & OS & $\begin{array}{c}\text { Data } \\
\text { extrapolated }\end{array}$ & $0.55(0.05,5.60)$ \\
\hline & & $\begin{array}{l}57 \\
57\end{array}$ & $\begin{array}{c}\text { Post-therapy } \\
\text { Baseline }\end{array}$ & $\begin{array}{l}13 \\
13\end{array}$ & $\begin{array}{l}\text { I-III } \\
\text { I-III }\end{array}$ & $\begin{array}{l}\text { RT-PCR } \\
\text { RT-PCR }\end{array}$ & $\begin{array}{c}3.5(2 / 57) \\
54.4(31 / 57)\end{array}$ & $\begin{array}{l}\text { OS } \\
\text { OS }\end{array}$ & $\begin{array}{c}\text { Data } \\
\text { extrapolated } \\
\text { Data } \\
\text { extrapolated }\end{array}$ & $\begin{array}{l}3.53(0.16,74.47) \\
1.39(0.14,13.75)\end{array}$ \\
\hline Guo T (2006) & China & 30 & Baseline & 37 & I-IV & RT-PCR & $43(13 / 30)$ & OS & $\begin{array}{c}\text { Data } \\
\text { extrapolated }\end{array}$ & $3.53(0.07,166.5)$ \\
\hline
\end{tabular}

Abbreviations: RT-PCR, reverse transcription-polymerase chain reaction; IE/IF, immunomagnetic enrichment/immunofluorescence staining; NR, not reported; DFS, disease-free survival; PFS, progression-free survival; OS, overall survival; pTNM, pathological tumour node metastasis. N, sample size; n, the number of positive patients; HR, hazard ratio; CI, confidence interval. 
overall survival (OS) $\left(I^{2}=48.4 \%, \mathrm{p}=0.036\right)$ showed different levels of heterogeneity (Figure 2). So we selected random-effects model for survival analysis.

The HRs for disease progression, measured by PFS and DFS, were available in 8 studies [9, 10, 28-30, 3537], accounting for 787 esophageal cancer patients. The HRs for OS were available in 5 studies [31, 33, 34, 38,
39], accounting for 264 cases. Analysis of PFS/DFS and OS revealed that, compared with CTC-negative patients, CTC-positive patients had a higher risk of disease progression $[\mathrm{HR}=2.32,95 \% \mathrm{CI}=1.57-3.43, \mathrm{p}<0.001]$ and worse overall survival $[\mathrm{HR}=2.64,95 \% \mathrm{CI}=1.69-$ $4.14, \mathrm{p}<0.001]$.

A

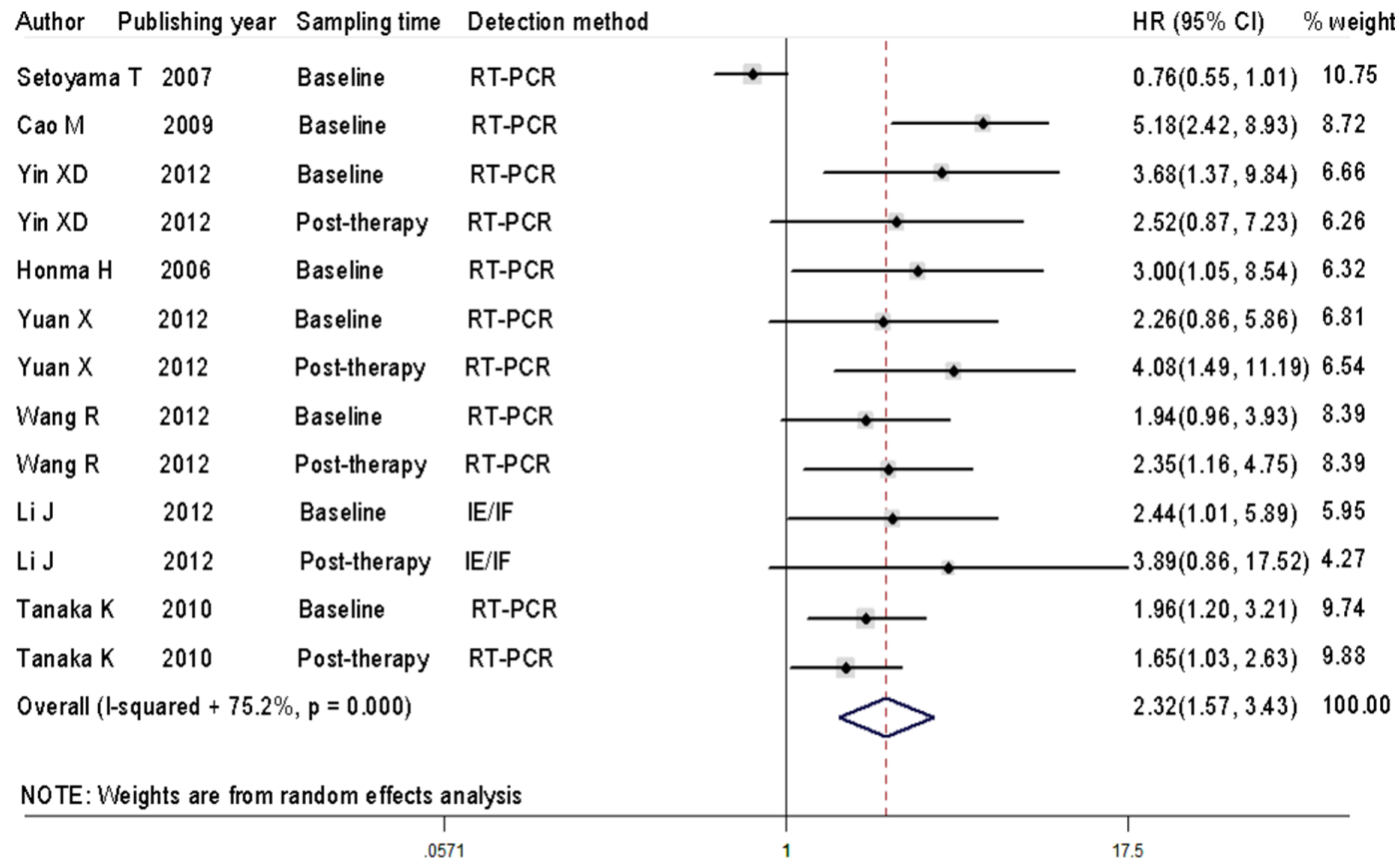

B

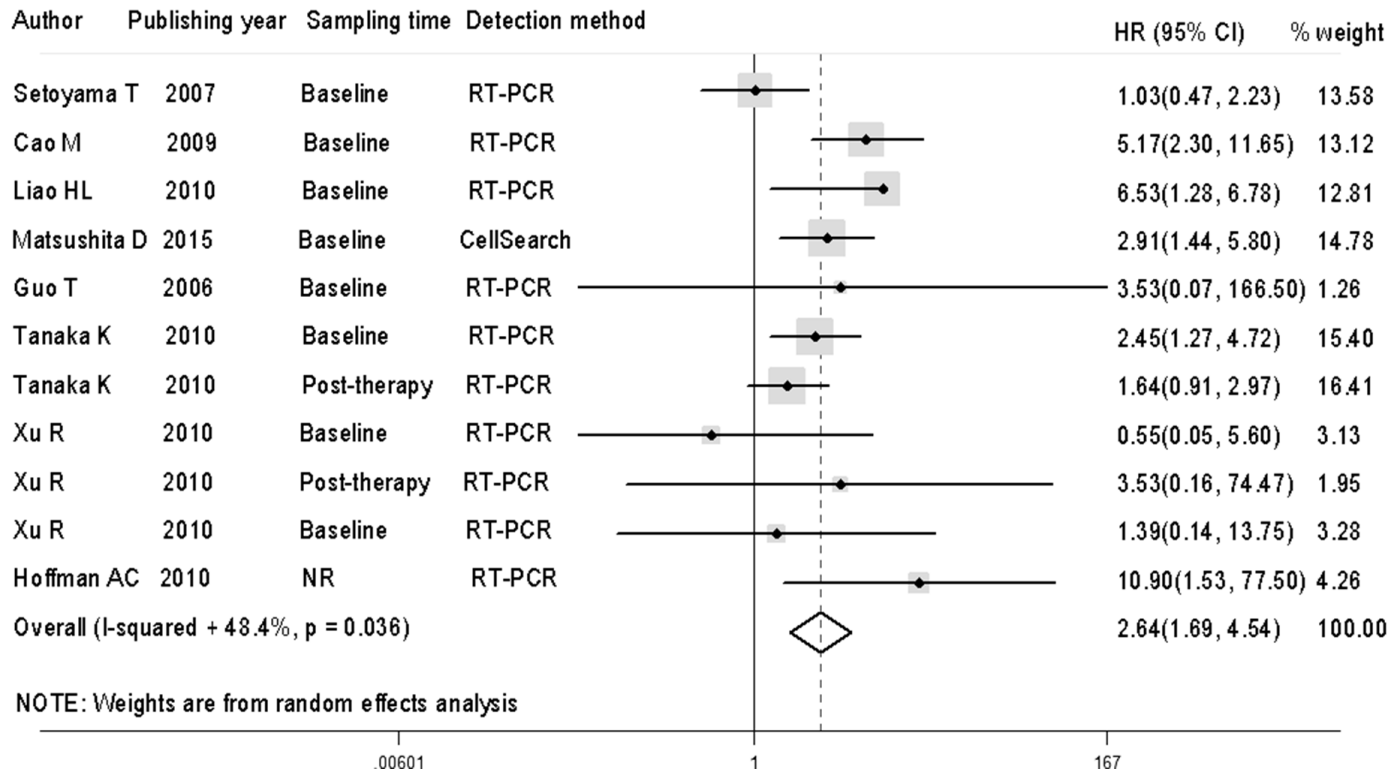

Figure 2: CTC-positive patients show a higher risk of disease progression and worse overall survival than CTCnegative patients. A. Forest plots of HRs and 95\% CIs for disease progression in esophageal cancer patients according to CTC-positive or negative status. B. Forest plots of HRs and 95\% CIs for overall survival in esophageal cancer patients according to CTC-positive or negative status. NR stood for not reported. 
Table 2: Subgroup analyses of the potential effects of CTCs on survival outcomes in esophageal cancer patients

\begin{tabular}{|c|c|c|c|c|c|c|c|c|}
\hline & \multicolumn{4}{|c|}{ Disease progression* } & \multicolumn{4}{|c|}{ Overall survival } \\
\hline & $\mathbf{n}$ & HR(95\%CI) & $p_{\text {heterogeneity }}$ & $I^{2}(\%)$ & $\mathbf{n}$ & HR(95\%CI) & $p_{\text {heterogeneity }}$ & $I^{2}(\%)$ \\
\hline \multicolumn{9}{|l|}{ Sampling time } \\
\hline NR & 1 & $0.76(0.56-1.03)$ & - & - & 2 & $2.80(0.29-27.53)$ & 0.0029 & 79.2 \\
\hline baseline & 7 & $2.65(1.95-3.60)$ & 0.334 & 12.5 & 7 & $3.39(2.22-5.20)$ & 0.285 & 19.0 \\
\hline post-therapy & 5 & $2.15(1.54-3.01)$ & 0.475 & 0 & 2 & $1.69(0.94-3.01)$ & 0.631 & 0 \\
\hline \multicolumn{9}{|l|}{ Sample size } \\
\hline$<50$ & 3 & $2.83(1.53-5.24)$ & 0.864 & 0 & 5 & $2.68(0.87-8.27)$ & 0.398 & 1.5 \\
\hline$\geqq 50$ & 10 & $2.21(1.41-3.47)$ & $<0.001$ & 79.9 & 6 & $2.65(1.59-4.43)$ & 0.009 & 67.3 \\
\hline \multicolumn{9}{|l|}{ Detection method } \\
\hline RT-PCR & 11 & $2.26(1.47-3.47)$ & $<0.001$ & 78.4 & 10 & $2.61(1.54-4.43)$ & 0.024 & 53.1 \\
\hline $\mathrm{IE} / \mathrm{IF}$ & 2 & $2.75(1.28-5.88)$ & 0.601 & 0 & & & & \\
\hline CellSearch & & & & & 1 & $2.81(1.96-4.02)$ & - & - \\
\hline \multicolumn{9}{|l|}{ Detection rate(\%) } \\
\hline$<30$ & 2 & $1.79(1.28-2.51)$ & 0.619 & 0 & 5 & $2.80(1.72-4.54)$ & 0.127 & 44.3 \\
\hline$\geqq 30$ & 11 & $2.52(1.51-4.20)$ & $<0.001$ & 79.1 & 5 & $1.83(0.66-5.07)$ & 0.052 & 57.3 \\
\hline \multicolumn{9}{|l|}{ CTC markers } \\
\hline CEA mRNA & 1 & $0.76(0.56-1.03)$ & - & - & 2 & $1.06(0.51-2.22)$ & 0.808 & 0 \\
\hline CK19 mRNA & 2 & $2.14(1.30-3.51)$ & 0.706 & 0 & 3 & $3.06(0.65-14.37)$ & 0.150 & 47.4 \\
\hline Survivin mRNA & 3 & $4.01(2.49-6.45)$ & 0.375 & 0 & 2 & $5.76(2.72-12.20)$ & 0.491 & 0 \\
\hline SCCA mRNA & 1 & $3.00(1.05-8.56)$ & - & - & 1 & $3.53(0.07-172.16)$ & - & - \\
\hline $\begin{array}{l}\text { CEA \& SCCA } \\
\text { mRNA }\end{array}$ & 2 & $1.79(1.28-2.51)$ & 0.619 & 0 & 2 & $1.96(1.27-3.05)$ & 0.373 & 0 \\
\hline $\begin{array}{l}\text { CEA, CK19 \& } \\
\text { Survivin mRNA }\end{array}$ & 2 & $3.08(1.50-6.35)$ & 0.606 & 0 & - & - & - & - \\
\hline
\end{tabular}

*Disease progression outcomes include disease-free survival (DFS) and progression-free survival (PFS).

Abbreviations: RT-PCR, reverse transcription-polymerase chain reaction; IE/IF, Immunomagnetic enrichment/ immunofluorescence staining; NR, not reported; CEA, carcinoembryonic antigen; CK19, cytokeratin 19; SCCA, squamous cell carcinoma antigen; CTC, circulating tumor cells; -, when the record number $\leqq 1$, the $p_{\text {hetergeneity }}$ and $I^{2}$ cannot be calculated.

\section{Subgroup analyses reject subgroup heterogeneity and confirm a higher risk of disease progression and worse overall survival in CTC-positive patients}

In order to explore sources of heterogeneity and to assess the diagnostic value of CTC status in different subgroups, we performed subgroup analysis (Table 2 ). In the subgroup analysis based on sampling time, a prognostic effect of CTC detection was confirmed in the analysis of samples collected at baseline (disease progression: $\mathrm{HR}=2.65,95 \% \mathrm{CI}=1.95-3.60, P_{\text {heterogeneity }}$ $=0.334, I^{2}=12.5 \%$; OS: HR $=3.55,95 \% \mathrm{CI}=2.46-5.13$, $P_{\text {heterogeneity }}=0.409, I^{2}=1.2 \%$ ), as well as samples collected post-therapy (disease progression: $\mathrm{HR}=2.15,95 \% \mathrm{CI}=$ 1.54-3.01, $P_{\text {heterogeneity }}=0.475, I^{2}=0.0 \%$; OS: HR $=1.64$, $95 \% \mathrm{CI}=0.91-2.96)$.

We also explored heterogeneity and the effect of CTC status on outcomes, according to detection methods.
CTCs detected by RT-PCR, IE/IF or CellSearch indicated an increased risk for both disease progression (RT-PCR: $\mathrm{HR}=2.26,95 \% \mathrm{CI}=1.47-3.47, \mathrm{P} P_{\text {heterogeneity }}<0.001, I^{2}=$ $78.4 \%$; IE/IF: $\mathrm{HR}=2.75,95 \% \mathrm{CI}=1.28-5.88, P_{\text {heterogeneity }}=$ $0.601, I^{2}=0.0 \%$; and OS (RT-PCR: HR $=2.61,95 \% \mathrm{CI}=$ $1.54-4.43, P_{\text {heterogeneity }}<0.024, I^{2}=53.1 \%$; CellSearch: HR $=2.81,95 \% \mathrm{CI}=1.96-4.02$, $)($ Table 2$)$.

We next assessed heterogeneity and the effect of CTC status on outcomes, according to CTC markers detected by RT-PCR. All markers except CEA mRNA indicated an increased risk for both disease progression and poor OS (disease progression: $\mathrm{HR}=0.76,95 \%$ $\mathrm{CI}=0.56-1.03 ; \mathrm{OS}: \mathrm{HR}=1.06,95 \% \mathrm{CI}=0.51-2.22$, $P_{\text {heterogeneity }}=0.808, I^{2}=0.0 \%$ ) (Table 2 ). Immportantly, single marker CTC detection was less effective (disease progression for CEA mRNA: 95\% CI = 0.561.03; OS for CEA mRNA: $95 \% \mathrm{CI}=0.51-2.22$; OS for CK19 mRNA: 95\% CI $=0.65-14.37$; OS for SCCA mRNA: $95 \% \mathrm{CI}=0.07-172.16$ ), and joint detection 
using multiple markers improved the effectiveness of CTC detection (disease progression for CEA \& SCCA mRNAs: $\mathrm{HR}=1.79,95 \% \mathrm{CI}=1.28-2.51$; DFS for CEA, CK19 \& Survivin mRNAs: HR $=3.08,95 \%$ CI $=1.50$ 6.35; OS for CEA \& SCCA mRNAs: HR $=1.96,95 \%$ $\mathrm{CI}=1.27-3.05)$. In addition, the effect of CTC status on patient outcomes was assessed separately for different detection rate and sample size. The result indicated that except OS for post-therapy (95\% CI $=0.94-3.01)$ and OS for sample size $(<50: 95 \% \mathrm{CI}=0.89-8.27)$, patients with positive CTCs had a higher risk for poor disease progression than patients with negative CTCs.

\section{Sensitivity and funnel plot analyses reveal no publication bias in overall and disease progression survival data}

Sensitivity analysis was performed on the impact of a single study on the overall results, after studies were removed one by one. It was revealed that no single study can significantly affect the results of the original analysis (Figure 3). In addition, the Begg test indicated that there were no significant publication bias (disease progression: $\operatorname{Pr}>|\mathrm{z}|=0.077>0.05$; OS, $\operatorname{Pr}>|\mathrm{z}|=0.755>0.05)$ (Figure 4), disease progression Egger test, $\operatorname{Pr}>|\mathrm{z}|=$

A
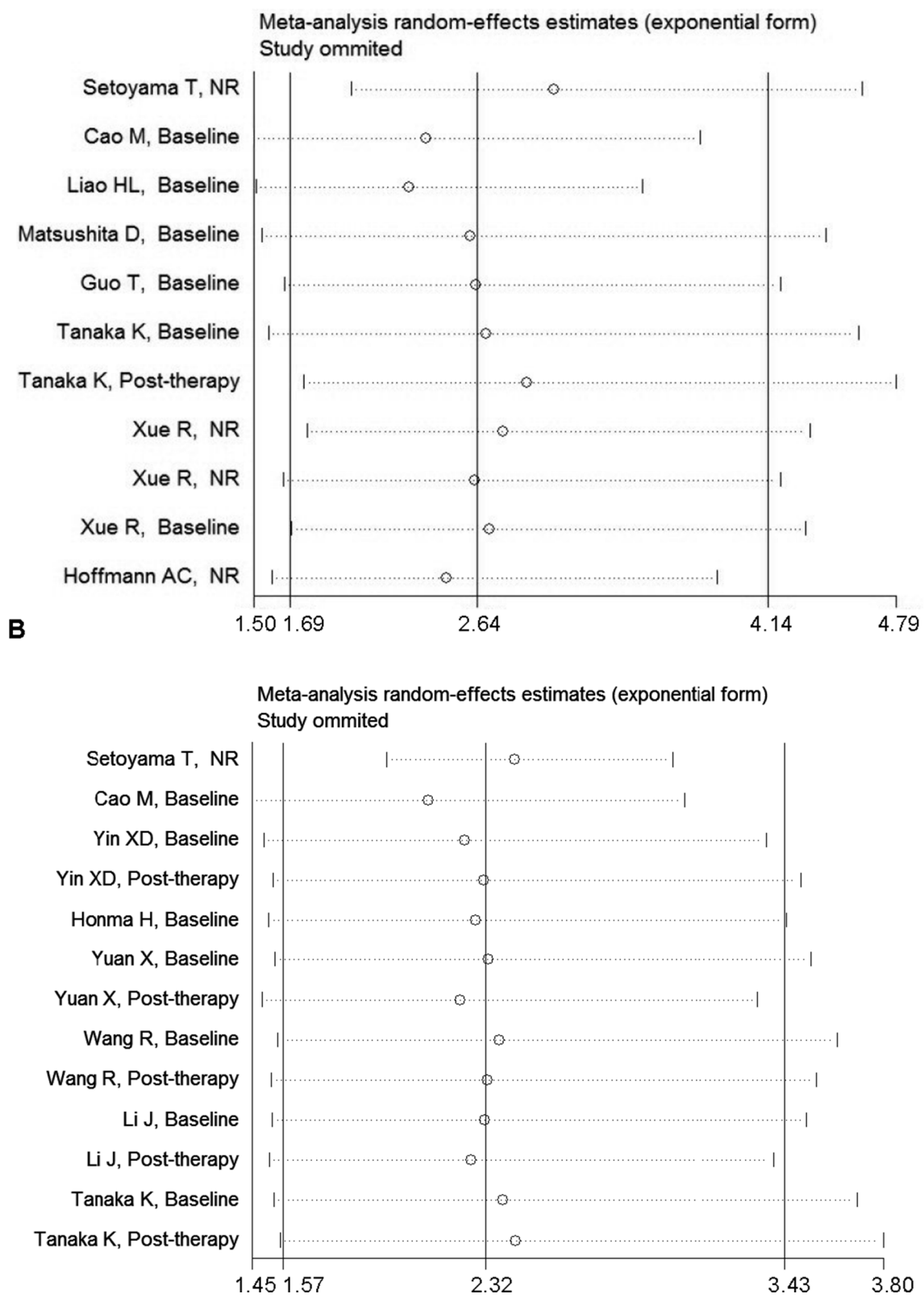

Figure 3: Sensitivity analysis reveals no publication bias in overall and disease progression survival data. A. Sensitivity analysis of overall survival. B. Sensitivity analysis of disease progression survival. NR stood for not reported. 
Begg's funnel plot with pseudo $95 \%$ confidence limits

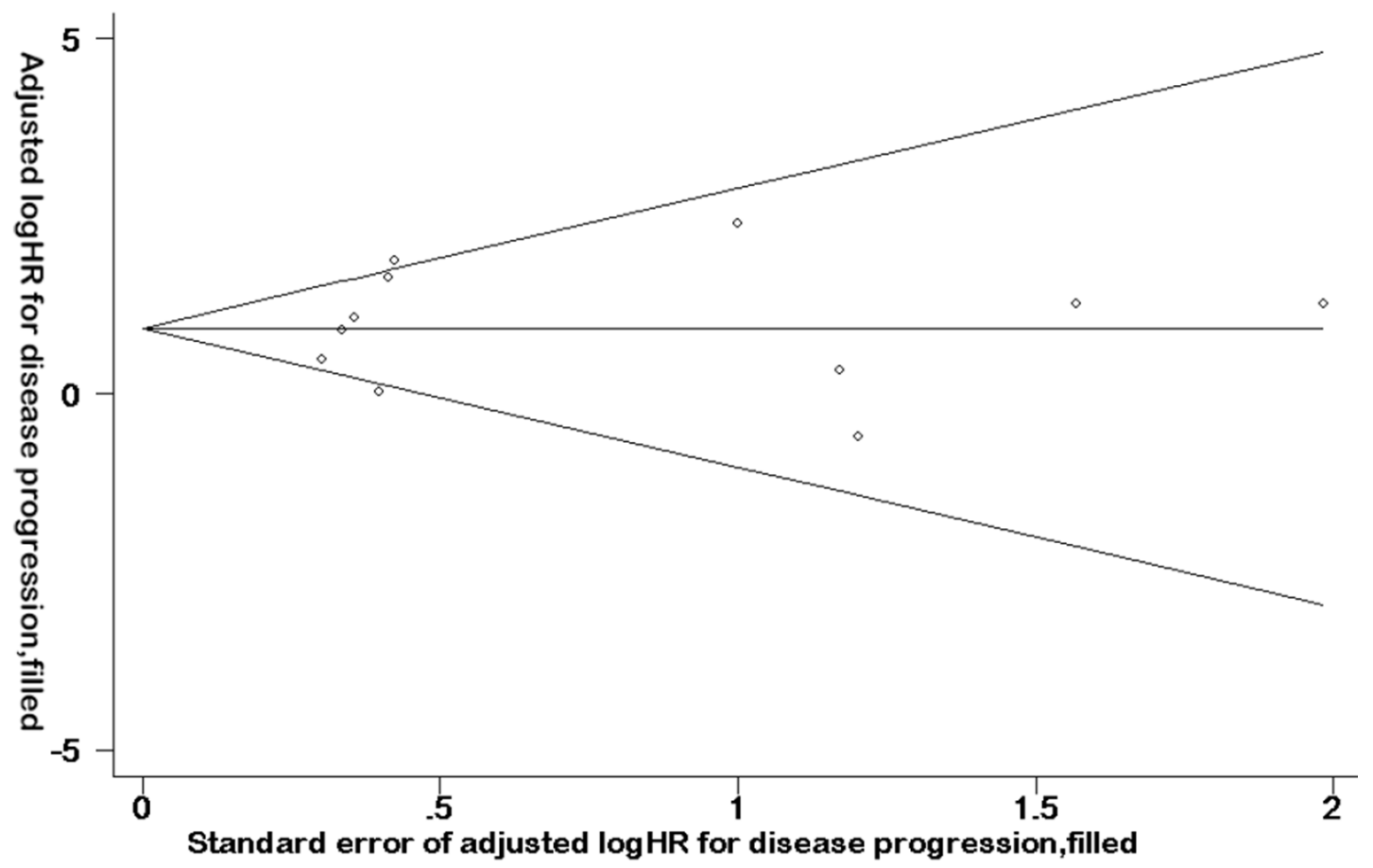

B

Begg's funnel plot with pseudo $95 \%$ confidence limits

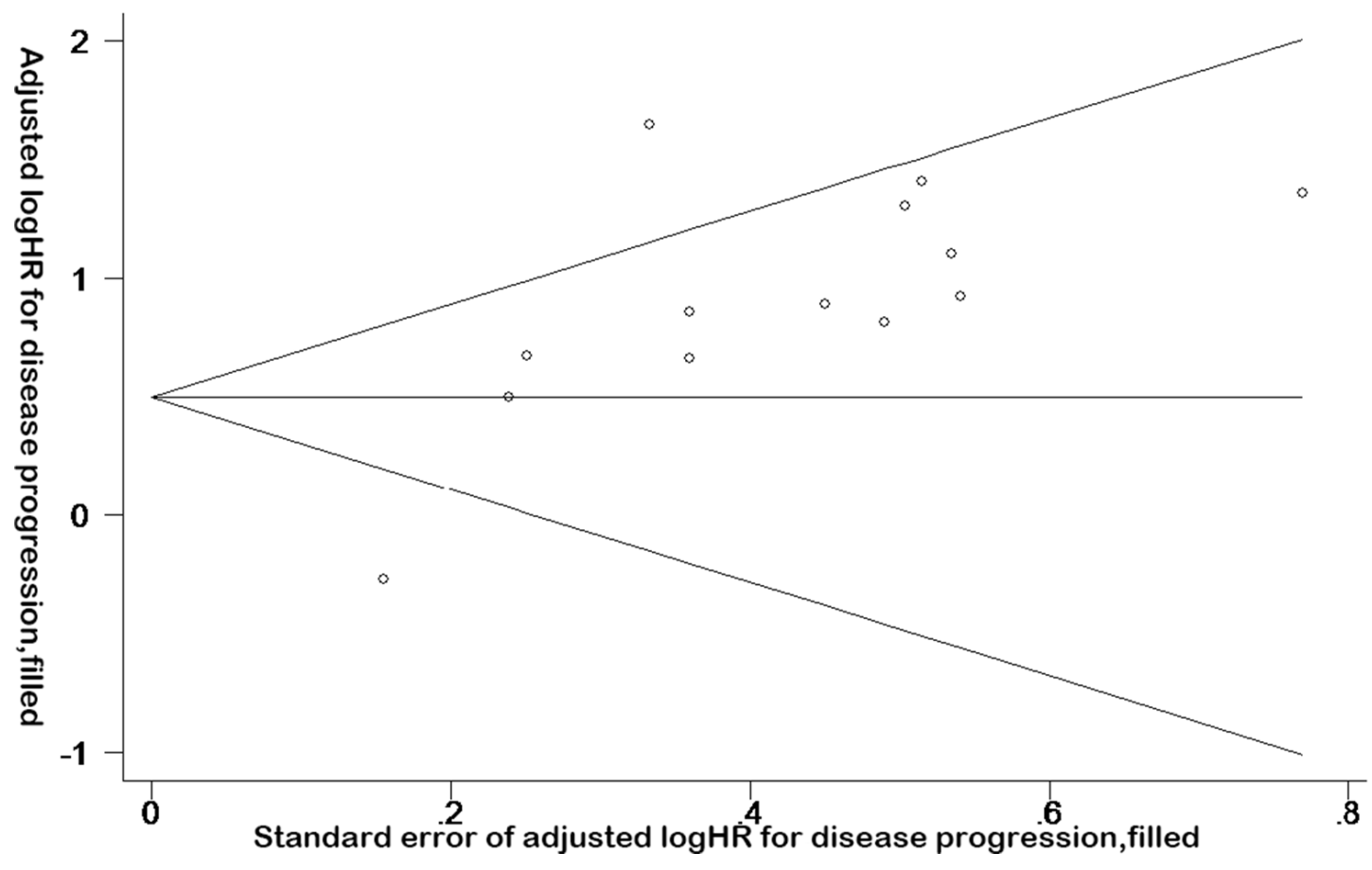

Figure 4: Funnel plot analysis reveals no publication bias in overall and disease progression survival data. A. Funnel plot of the studies on overall survival. B. Funnel plot of the studies on disease progression survival. 
0.001. As the two test results are inconsistent, in order to further examine publication bias, literature disease progression was analysed using the trim and fill method with greater statistical power as below.

\section{Trim and fill method reveals publication bias in disease progression data}

Trim and fill method was developed by Taylor and Tweedie [40]. According to this method, small sample studies were removed and added so as to make the funnel plot symmetric. By removing part of the studies and adding it back, the effects before and after the merger were analysed. If the same conclusion could be drawn, the publication bias was insignificant, and the result was relatively stable [41].

HRs generated by the fixed effects model and random effects model before trimming were $0.498(0.322$ $0.673)$ and $0.841(0.448-1.233)$, indicating that $95 \%$ confidence interval was not statistically significant before trimming (Figure 5). However, after adding six points, the HRs were $1.456(1.239-1.712)$ and 1.766 (1.2562.482 ). The results showed that $95 \%$ confidence interval was statistically significantly different after trimming, indicating that the result was unstable. After adding six points to eliminate the impact of publication bias, funnel plot center move to the right (Figure 5). Taken together, the trim and fill method revealed that the publication bias existed in the literature disease progression data.

\section{DISCUSSION}

CTCs are tumor cells released into the peripheral circulation from primary or metastatic tumors spontaneously or due to clinical procedures [42]. Detection of CTCs help monitor tumor recurrence, metastasis and therapeutic responses in real-time, predict patient prognosis and identify mechanisms for tumor progression and metastasis [43]. Recent meta-analyses demonstrate that detection of CTCs in the peripheral blood is an independent prognosticator of poor survival in triple negative breast cancer, ovarian and gastric cancer patients [44-46].

This is the first meta-analysis of CTCs in esophageal squamous cell carcinoma patients, and provide the first comprehensive evidence for CTCs as a biomarker for poor prognosis in esophageal squamous cell carcinoma patients. The results of this study showed that CTC-positive patients had worse prognosis than CTC-negative patients. To explore sources of heterogeneity and the diagnostic value of CTC status, we further performed subgroup analysis, and found that both the baseline and post-therapy
Filled funnel plot with pseudo $95 \%$ confidence limits

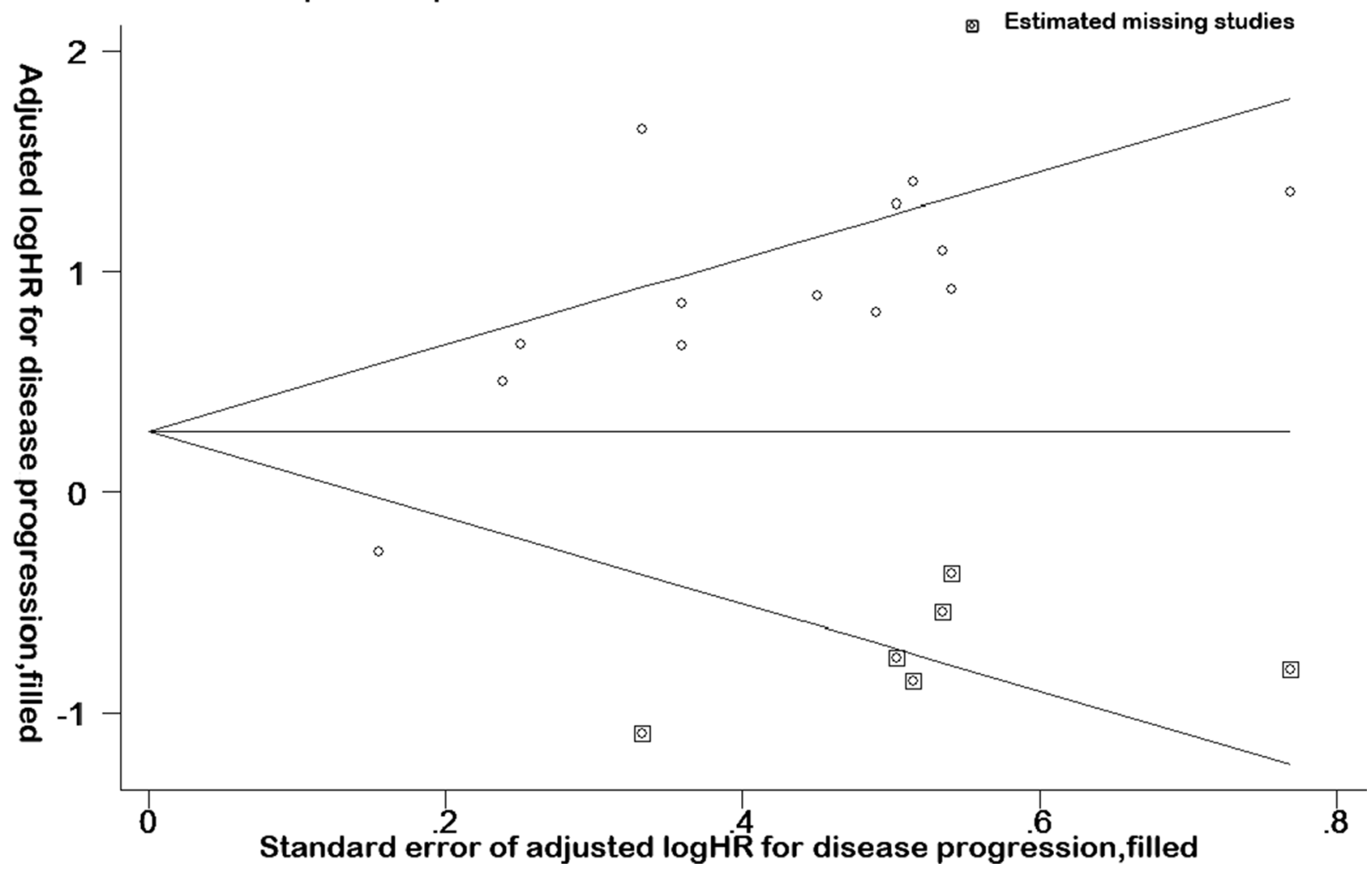

Figure 5: Trim and fill method reveals publication bias in disease progression data. Funnel plot and complement funnel plot of the studies on disease progression. The box in this figure is a complement plot, which was used to estimated missing studies. 
positive CTCs were associated with poor prognosis in patients with esophageal cancer. The results suggest that CTCs can be used as a biomarker for poor prognosis in esophageal cancer patients, and that monitoring CTCs at different time points of treatments through repeated CTC testing better predicts patient prognosis.

In this study, subgroup analysis, according to different CTC detection methods, showed poorer prognosis in CTC-positive patients than CTC-negative patients, and showed heterogeneity due to RT-PCR method. To detect the source of heterogeneity in literature CTC studies by RT-PCR, we analysed data from different subsets of RTPCR markers for CTC detection. Cochrane Q test and $I^{2}$ tests of the different CTC markers showed the sources of heterogeneity were eliminated. In addition, our results showed that single marker CTC detection was less effective, and that joint detection using multiple markers can improve the effectiveness of CTC detection in patients in the clinic.

In this study, sensitivity analysis and trim and fill method were also performed. Sensitivity analysis revealed that no single study can significantly affect the results of the original analysis, but the trim and fill method revealed that the publication bias existed in the literature disease progression data.

There were limitations in our meta-analysis. Data collected from studies performed with different experimental approaches by different research groups may lead to significant inconsistency. However, our metaanalysis confirms that detection of CTCs independently correlates with poor prognosis in esophageal cancer patients, irrespective of experimental approaches by different groups. It is therefore safe to conclude that detection of CTCs independently correlates with poor prognosis in esophageal cancer patients.

In summary, this study indicates that CTCs are an important biomarker for esophageal squamous cell carcinoma diagnosis, metastasis and recurrence, and an effective predictor for poor patient prognosis. Detection of CTCs can be used to guide clinical treatments.

\section{MATERIALS AND METHODS}

\section{Study selection}

A comprehensive literature search was performed to identify relevant articles on esophageal CTCs in EMbase, PubMed, EBSCO, OVID, Cochrane Database, CNKI, WanFangdata and VIPdata without any restriction (up to February 2016). The search key words included combinations of carcinoma, cancer, tumor, tumour, circulating tumor cell, circulating tumor cells, circulating tumour cell, circulating tumour cells, CTC, CTCs, esophageal or oesophageal. Studies were considered eligible if they fulfilled all of the following criteria: (1) retrospective or prospective cohort studies; (2) the progression or survival of esophageal cancer patients was stratified and CTC status was verified; (3) hazard ratios (HRs) and 95\% confidence intervals (CIs) were provided, or sufficient information was provided for extrapolating them. For studies with overlapping data, we only kept the study with the larger sample size. The study selection process was performed independently by two authors, and any discrepancy was resolved by discussion or consultation with a third party. We did not assign a quality score to each study, because no such score assessment has received a general consensus for non-randomized prognostic studies [45]. Instead, we performed the widely recommended subgroup and sensitivity analyses to determine the potential effects of CTC status on the prognosis of esophageal cancer patients.

\section{Data collection}

Data collected from each eligible study included publication year, author names, country of origin, number of subjects analyzed, esophageal cancer stage, median follow-up day, blood collection time, detection method, detection rate, and cut-off values for CTC status. We also recorded prognostic outcomes including progressionfree survival (PFS)/disease-free survival (DFS), overall survival (OS), survival curves, $\mathrm{HR}$ and $95 \% \mathrm{CI}$, if available, regardless of whether they were tested by multivariate analysis. When more than one blood sample per subject was collected at different time points, each sampling time point was documented and categorized as "baseline" or "mid- or post-therapy". When more than one method was applied to detect CTCs, all results were considered as independent data sets.

\section{Statistical methods}

The HR and the 95\% CI were directly recorded from each study or extrapolated. Survival data were extracted from survival graphs in high-quality PDF documents through Engauge Digitizer 4.1 software, lnHR and SelnHR were calculated, and survival analysis was performed with $\mathrm{R}$ programming language [47, 48]. The fixed effect model or random effect model was employed to calculate $\mathrm{HR}$ and $95 \% \mathrm{CI}$, and statistically significant effect of the combined data was analyzed by the $Z$ value $[47,48]$. Heterogeneity between studies was examined using the Cochran $\mathrm{Q}$ test and quantitative $I^{2}$ test. If $\mathrm{p}$ for the Cochran Q test was $<0.05$ or $I^{2}$ for the $I^{2}$ test was $>50 \%$, study heterogeneity was considered to exist, and random-effects model (DerSimonian Laird) was further used for analysis [49]. If there was no heterogeneity in each study, the fixed effects model (Mantel-Haenszel method) was used for further analysis [50]. Subgroups were identified according to before and after treatments, testing methods and CTC markers, to explore sources of heterogeneity among the groups. Deleting studies one by one allowed sensitivity analysis to assess the impact of 
a single study on the overall results. Begger funnel plot, Begg test [41] and reduced fill method [51] analyses were used to examine whether there were publication deviations in the published literature, and to assess the authenticity of the original analysis results. Meta analyses were performed using STATA 12. 0 software.

\section{ACKNOWLEDGMENTS}

The authors thank staff in their laboratories for constructive comments.

\section{CONFLICTS OF INTEREST}

The authors have no potential conflicts of interest to disclose.

\section{REFERENCES}

1. Tanaka M, Takeuchi H, Osaki Y, Hiraiwa K, Nakamura R, Oyama T, Takahashi T, Wada N, Kawakubo H, Saikawa Y, Omori T, Kitagawa Y. Prognostic significance of circulating tumor cells in patients with advanced esophageal cancer. Esophagus. 2015; 12:352-359.

2. Seeberg LT, Waage A, Brunborg C, Hugenschmidt H, Renolen A, Stav I, Bjornbeth BA, Brudvik KW, Borgen EF, Naume B, Wiedswang G. Circulating tumor cells in patients with colorectal liver metastasis predict impaired survival. Annals of surgery. 2015; 261:164-171.

3. Jemal A, Center MM, DeSantis C, Ward EM. Global patterns of cancer incidence and mortality rates and trends. Cancer epidemiology, biomarkers \& prevention. 2010; 19:1893-1907.

4. Godfrey TE, Raja S, Finkelstein SD, Gooding WE, Kelly LA, Luketich JD. Prognostic value of quantitative reverse transcription-polymerase chain reaction in lymph nodenegative esophageal cancer patients. Clin Cancer Res. 2001; 7:4041-4048.

5. Kijima F, Natsugoe S, Takao S, Aridome K, Baba M, Yoshifumi M, Eizuru Y, Aikou T. Detection and clinical significance of lymph node micrometastasis determined by reverse transcription-polymerase chain reaction in patients with esophageal carcinoma. Oncology. 2000; 58:38-44.

6. Massague J, Obenauf AC. Metastatic colonization by circulating tumour cells. Nature. 2016; 529:298-306.

7. Joosse SA, Pantel K. Biologic challenges in the detection of circulating tumor cells. Cancer Res. 2013; 73:8-11.

8. Alix-Panabieres C, Pantel K. Challenges in circulating tumour cell research. Nature reviews Cancer. 2014; 14:623-631.

9. Setoyama T, Natsugoe S, Okumura H, Matsumoto M, Uchikado Y, Aikou T. Isolated tumour cells in blood and E-cadherin expression in oesophageal squamous cell cancer. The British journal of surgery. 2007; 94:984-991.
10. Cao M, Yie SM, Wu SM, Chen S, Lou B, He X, Ye SR, Xie K, Rao L, Gao E, Ye NY. Detection of survivin-expressing circulating cancer cells in the peripheral blood of patients with esophageal squamous cell carcinoma and its clinical significance. Clinical \& experimental metastasis. 2009; 26:751-758.

11. Ren C, He P, Zhang J, Zheng Z, Qiao Y, Zhao X. Malignant characteristics of circulating tumor cells and corresponding primary tumor in a patient with esophageal squamous cell carcinoma before and after surgery. Cancer biology \& therapy. 2011; 11:633-638.

12. Li H, Song P. Circulating Tumor Cell Analyses in Patients With Esophageal Squamous Cell Carcinoma Using Epithelial Marker-Dependent and -Independent Approaches. Medicine. 2015; 94:1-9.

13. Ikoma D, Ichikawa D, Ueda Y, Tani N, Tomita H, Sai S, Kikuchi S, Fujiwara H, Otsuji E, Yamagishi H. Circulating tumor cells and aberrant methylation as tumor markers in patients with esophageal cancer. Anticancer Res. 2007; 27:535-539.

14. Fujii K, Goto A, Matsunaga Y, Hasegawa Y, Sukawa Y, Suzuki K, Yonezawa K, Abe T, Itoh A, Shinomura Y, Iimura Y, Hasegawa N, Nakamura H, Yoshida Y. Primary malignant melanoma of the esophagus--detection of circulating tumor cells. Jap J Cancer \& Chemotherapy. 2010; 37:1539-1543.

15. Zhan XK, Sun YK, Zhang W, Wang JW. Clinical analysis of 81 cases with primary small cell carcinoma of the esophagus. Chin J Oncol. 2008; 30:926-929.

16. Zhang Y, Liu YP, Du K, Wang H, Wang XL. Expression and clinical significance of PI3K in esophageal squamous cell carcinoma. Chin J Oncol. 2011; 33:594-598.

17. Koike M, Hibi K, Kasai Y, Ito K, Akiyama S, Nakao A. Molecular detection of circulating esophageal squamous cell cancer cells in the peripheral blood. Clin Cancer Res. 2002; 8:2879-2882.

18. Matsuda S, Takeuchi H, Fukuda K, Nakamura R, Takahashi T, Wada N, Kawakubo H, Saikawa Y, Omori T, Kitagawa Y. Clinical significance of plasma fibrinogen level as a predictive marker for postoperative recurrence of esophageal squamous cell carcinoma in patients receiving neoadjuvant treatment. Diseases of the esophagus. 2014; 27:654-661.

19. Hashimoto T, Kajiyama Y, Tsutsumi-Ishii Y, Nagaoka I, Tsurumaru M. Circulating micrometastases of esophageal cancer detected by carcinoembryonic antigen mRNA reverse transcriptase-polymerase chain reaction: clinical implications. Diseases of the esophagus. 2008; 21:690-696.

20. Kaganoi J, Shimada Y, Kano M, Okumura T, Watanabe G, Imamura M. Detection of circulating oesophageal squamous cancer cells in peripheral blood and its impact on prognosis. The British journal of surgery. 2004; 91:1055-1060.

21. Brattstrom D, Wagenius G, Sandstrom P, Dreilich M, Bergstrom S, Goike H, Hesselius P, Bergqvist M. Newly developed assay measuring cytokeratins 8,18 and 19 in 
serum is correlated to survival and tumor volume in patients with esophageal carcinoma. Diseases of the esophagus. 2005; 18:298-303.

22. Ito $H$, Kanda $T$, Nishimaki $T$, Sato $H$, Nakagawa $S$, Hatakeyama K. Detection and quantification of circulating tumor cells in patients with esophageal cancer by realtime polymerase chain reaction. Journal of experimental \& clinical cancer research. 2004; 23:455-464.

23. Nakashima S, Natsugoe S, Matsumoto M, Miyazono F, Nakajo A, Uchikura K, Tokuda K, Ishigami S, Baba M, Takao S, Aikou T. Clinical significance of circulating tumor cells in blood by molecular detection and tumor markers in esophageal cancer. Surgery. 2003; 133:162-169.

24. Geng Q. Detection and quantification of circulating tumor cells in esophageal squamous cancer by real-time fluorescent quantitative reverse transcriptase-polymerase chain reaction. Chin J Exp Surg. 2010; 27:1203-1205.

25. Liu Z, Jiang M, Zhao J, Ju H. Circulating tumor cells in perioperative esophageal cancer patients: quantitative assay system and potential clinical utility. Clin Cancer Res. 2007; 13:2992-2997.

26. Bobek V, Matkowski R, Gurlich R, Grabowski K, Szelachowska J, Lischke R, Schutzner J, Harustiak T, Pazdro A, Rzechonek A, Kolostova K. Cultivation of circulating tumor cells in esophageal cancer. Folia histochemica et cytobiologica. 2014; 52:171-177.

27. Sclafani F, Smyth E, Cunningham D, Chau I, Turner A, Watkins D. A pilot study assessing the incidence and clinical significance of circulating tumor cells in esophagogastric cancers. Clinical colorectal cancer. 2014; 13:94-99.

28. Tanaka K, Yano M, Motoori M, Kishi K, Miyashiro I, Shingai T, Gotoh K, Noura S, Takahashi H, Ohue M, Yamada T, Ohigashi H, Yamamoto T, Yamasaki T, Doki Y, Ishikawa O. CEA-antigen and SCC-antigen mRNA expression in peripheral blood predict hematogenous recurrence after resection in patients with esophageal cancer. Annals of surgical oncology. 2010; 17:2779-2786.

29. Li J. Detection of circulating tumor cells from peripheral blood in patients with esophagealsquamous cell carcinoma and its clinical significance. Southern Medical University. 2007; Thesis.

30. Yin XD, Yuan X, Xue JJ, Wang R, Zhang ZR, Tong JD. Clinical significance of carcinoembryonic antigen-, cytokeratin 19-, or survivin-positive circulating tumor cells in the peripheral blood of esophageal squamous cell carcinoma patients treated with radiotherapy. Diseases of the esophagus. 2012; 25:750-756.

31. Liao H. CK19mRNA expression in peripheral blood of preoperative patients with esophageal squamous cell carcinoma and its clinical significance. Sun Yat-sen University. 2010; Thesis.

32. Reeh M, Effenberger KE, Koenig AM, Riethdorf S, Eichstadt D, Vettorazzi E, Uzunoglu FG, Vashist YK,
Izbicki JR, Pantel K, Bockhorn M. Circulating Tumor Cells as a Biomarker for Preoperative Prognostic Staging in Patients With Esophageal Cancer. Annals of surgery. 2015; 261:1124-1130.

33. Matsushita D, Uenosono $\mathrm{Y}$, Arigami $\mathrm{T}$, Yanagita $\mathrm{S}$, Nishizono Y, Hagihara T, Hirata M, Haraguchi N, Arima H, Kijima Y, Kurahara H, Maemura K, Okumura H, Ishigami S, Natsugoe S. Clinical Significance of Circulating Tumor Cells in Peripheral Blood of Patients with Esophageal Squamous Cell Carcinoma. Annals of surgical oncology. 2015; 22:3674-3680.

34. Hoffmann AC, Vallbohmer D, Grimminger P, Metzger R, Prenzel KL, Hoelscher AH, Brabender J. Preoperative survivin mRNA detection in peripheral blood is an independent predictor of outcome in esophageal carcinoma. Pharmacogenomics. 2010; 11:341-347.

35. Honma H, Kanda T, Ito H, Wakai T, Nakagawa S, Ohashi M, Koyama Y, Valera VA, Akazawa K, Hatakeyama K. Squamous cell carcinoma-antigen messenger RNA level in peripheral blood predicts recurrence after resection in patients with esophageal squamous cell carcinoma. Surgery. 2006; 139:678-685.

36. Yuan X, Yin X, Xue J. Clinical significance of survivin mRNA detection in peripheral blood of esophageal cancer patients treated with radiotherapy. Acta Universitis Nanjing. 2012; 32:231-235.

37. Wang $\mathrm{R}$, Zhang $\mathrm{Y}$, Yin $\mathrm{X}$. Clinical significance of CK19mRNA detection in peripheral blood of esophageal cancer patients treated with radiotherapy. Oncology Progress. 2012; 10:84-88.

38. Xue R. CEAmRNA, CK19mRNA expression in peripheral blood of preoperative and postoperative esophageal cancer patients and its clinical significance. Shantou University. 2010; Thesis.

39. Guo T. Detection of micrometastasis by nested RT-PCR in peripheral blood from the patient with esophageal squamous cell carcinoma and its clinical significance. Zhengzhou University. 1998; Thesis.

40. Taylor SJ, Tweedie RI. Practical estimates of the effect of publication bias in meta-analysis. Australias Epidemiolist. 1998; 5:14-17.

41. Begg CB, Mazumdar M. Operating characteristics of a rank correlation test for publication bias. Biometrics. 1994; 50:1088-1101.

42. Soeth E, Grigoleit U, Moellmann B, Roder C, Schniewind B, Kremer B, Kalthoff H, Vogel I. Detection of tumor cell dissemination in pancreatic ductal carcinoma patients by CK 20 RT-PCR indicates poor survival. Journal of cancer research and clinical oncology. 2005; 131:669-676.

43. Rahbari NN, Aigner M, Thorlund K, Mollberg N, Motschall E, Jensen K, Diener MK, Buchler MW, Koch M, Weitz J. Meta-analysis shows that detection of circulating tumor cells indicates poor prognosis in patients with colorectal cancer. Gastroenterology. 2010; 138:1714-1726. 
44. Huang X, Gao P, Sun J, Chen X, Song Y, Zhao J, Xu H, Wang Z. Clinicopathological and prognostic significance of circulating tumor cells in patients with gastric cancer: a meta-analysis. Int J Cancer. 2015; 136:21-33.

45. Lu YJ, Wang P, Wang X, Peng J, Zhu YW, Shen N. The significant prognostic value of circulating tumor cells in triple-negative breast cancer: a meta-analysis. Oncotarget. 2016; 7:37361-37369. doi: 10.18632/oncotarget.8156.

46. Zhou Y, Bian B, Yuan X, Xie G, Ma Y, Shen L. Prognostic Value of Circulating Tumor Cells in Ovarian Cancer: A Meta-Analysis. PLoS One. 2015; 10:e0130873.

47. Parmar MK, Torri V, Stewart L. Extracting summary statistics to perform meta-analyses of the published literature for survival endpoints. Statistics in medicine. 1998; 17:2815-2834.
48. Tierney JF, Stewart LA, Ghersi D, Burdett S, Sydes MR. Practical methods for incorporating summary time-to-event data into meta-analysis. Trials. 2007; 8:16.

49. Higgins JP, Thompson SG. Quantifying heterogeneity in a meta-analysis. Statistics in medicine. 2002; 21:1539-1558.

50. Harris RJ, Bradburn MJ, J. DJ, Harbord RM, Altman DG, Sterne JAC. Metan: fixed- and random-effects metaanalysis. Stata J. 2003; 8:3-28.

51. Duval S, Tweedie R. Trim and fill: A simple funnel-plotbased method of testing and adjusting for publication bias in meta-analysis. Biometrics. 2000; 56:455-463. 